\title{
Broiler verimlilik indeksi ile hijyen değişkenleri arasındaki ilişkiler*
}

\author{
Şükrü GÜRLER', Öznur POYRAZ², Mehmet Nurullah ORMAN³ \\ I Orman Bakanlığı MP ve Av-Yaban Hayatı Gen. Müd., Ankara; ${ }^{2}$ Ankara Üniversitesi, Veteriner Fakültesi, Zootekni Anabilim \\ Dalı, ${ }^{3}$ Ankara Üniversitesi, Veteriner Fakültesi, Biyometri Anabilim Dal, Ankara
}

\begin{abstract}
Özet: Bu araştırma bazı hijyen değişkenlerinin broiler verimliliğini ne ölçiide etkilediğini belirlemek amacıyla yapılmıştır. Araştırma, Nisan 1999 - Ekim 2000 tarihleri arasında 298 kümeste üretilen 1430 sürü üzerinde yürütülmüştür. Broiler verimliliğinin ölçüsü olarak Broiler Verimlilik İndeksi (BVI), hijyen koşullarının ölçüisü olarak da iki sonuçlu olarak tanımlanan 37 değişken kullanılmışır. Hijyen değişkenleri ile BVİ arasında bir bilgisayar paket programda, adım adım regresyon analizi uygulanarak her sürünüin içinde bulunduğu hijyen koşullarının ölçüsii olacak bir hijyen indeksi (HI) geliştirilmiştir. Regresyon analizi sonucunda salgın hastalık, ölen hayvanların uzaklaştırılması, kümes yapısı, kümesin çevre kümeslerden uzaklığı, üretim dönemi sonunda altlık materyalinin uzaklaştırılması, kümes girişinde dezenfeksiyon, kümesin yaşı, kümes kapasitesi, kümes havalandırması, üretim çiftliğ̊nde başka tür ya da yaş grubundan kanatłı hayvanlann varlığı ve ısıtma değişkenleri hijyen indeksinde yer almıştır. Seçilen regresyon modelinin belirtme katsayısı $\left(\mathrm{R}^{2}\right)$ modelin, broiler verimlilik indeksi açısından sürüler arasında gözlenen farklılığın \% 49'unu açıklayabildiğini göstermiştir. BVI ile Hi arasında pozitif ve önemli $(\mathrm{p}<0.01)$ bir ilişki $(\mathrm{r}=0.703)$ bulunmuştur. Araştırma sonuçlarına göre, broiler verimliliğinin hijyen değişkenlerinden önemli ölçüde etkilendiği ve kümes, ekipman, sürü idaresi ve sağlık koruma ile ilgili hijyen değişkenlerinde yapılacak bazı iyileştirmeler ile verimlilikte önemli artışların sağlanabileceği söylenebilir.

Anahtar kelimeler: Broiler, broiler verimlilik indeksi, hijyen, sağlık koruma
\end{abstract}

\section{Relationship between broiler performance and hygiene variables}

Abstract: The objective of this research was to determine the effects of some hygiene variables on performance of commercial broilers. Investigation data coming from 1430 commercial broiler flocks kept on 298 broiler production units were collected in sixteen months of time from April 1999 to October 2000. European Efficiency Factor (EEF: dependent variable) was used as a quantitative measure of the flock performance. Thirty seven hygiene variables (independent variables) with two responses were defined. The stepwise regressions were performed using of a software program. An index for hygiene (HI) variables associated with EEF was developed at the end of analysis. In the final regression model, the following hygiene variables were found to be significantly $(p<0.01)$ associated with broiler performance: epidemic diseases, dead-bird management, structure of the house, distance to the nearest poultry house, removal of litter in the end of rearing period, disinfection of the footwear at the entrance of broiler house, age of broiler house, flock size, type of ventilation system, presence of different age groups or other poultry in the farm, and heating system. The coefficient of determination (R2) showed that the model could explain $49 \%$ of the differences in flock performance. HI was positively and significantly $(\mathrm{p}<0.01)$ correlated with EEF $(r=0.703)$. As the result of this investigation it can be stated that efficiency of broiler flocks can be improved by means of improving the hygiene variables related with house, equipment, management and bio-security.

Key words: Broiler, curopean efficiency factor, hygiene, Bio-security

\section{Giriş}

Hayvansal üretimde üstün verim ancak sağlıklı sürülerden elde edilebilir. Sürï sağlığının gereği gibi korunması için sağlık koruma kurallarına titizlikle uyulmalıdır. Sağlık koruma kuralları; hastalık etkenlerinin uzak tutulması (izolasyon), hayvanlar için sağlıklı yaşam koşullarının sağlanması (hijyen) ve üretim bölgesi için risk oluşturan hastalık etkenlerine karşı hayvanların bağışık hale getirilmesi (aşılama) uygulamalarından oluşmaktadır $(2,3,22,28)$. Sağlıklı yaşam koşulları olarak tanımlanabilen ve bu araştırmanın konusunu oluşturan "hijyen" in kümes koşullarında doğrudan bir değerlendirme ölçüsü yoktur. Bunun için hijyen koşulları ile ilgili gözlemlenebilen değişkenlerden yararlanılarak gözlemlenemeyen değişken (hijyen) hakkında sayısal bir değer elde edilebilir. Bu amaçla, hijyen koşulları ile verim özelikleri arasındaki doğrusal ilişkiden yararlanılmaktadır. Ticari yumurtacı sürülerde yumurta verimi ile ilişkili hijyen değişkenleri için bir indeks geliştirmiş ve geliştirilen indeks kullanılarak sürülerin içinde bulundurulduklanı hijyen koşullarının ölçüü olacak bir sayısal değer elde edildiği bildirilmiştir (20).

Hijyen değişkenleri ile ilgili araştırmalarda öncelikli olarak hijyen koşulları ile ilgili bağımsız değişkenler tanımlanmakta ve bu değişkenler ile araştırma konusunu oluşturan özelliğe ait sonuçlar arasındaki ilişkiler araştırılmaktadır. Bu amaçla yapılmış bazı araştırmalarda, üretim kümesinin girişinde dezenfeksiyon yapılmaması ve kümes içinde iş elbisesi giyilmemesi $(11,13,15,16,30)$, kümeste yeterli havalandırmanın yapılamaması (17), kümes içinde yeterli hava akımının sağlanamaması $(14,19,23,27)$, üretim çiftliğinde farklı tür, ırk ya da yas grubundan hayvanların bulunması ( 1 ,

\footnotetext{
* Ayn adı doktora tezinden özetlenen bu çalışma TÜBITTAK (VHAG/ADP-1553) tarafından desteklenmiştir
} 
$13,15,18,23)$, kümesin çevre kümeslerden yeterli uzaklıkta bulunmaması, bir bakıcının birden çok kümesle ilişkisinin olması ve kümesin ziyaret edilme sıklığ $1(1,12,23,24)$, kümesin yapısı, ölen hayvanların günlük olarak toplanıp uygun bir şekilde uzaklaştırılmaması $(11,12,14)$ değişkenleri verim özellikleri ve bazı sağlık sorunları için önemli risk faktörleri olarak bildirilmiştir.

Hijyen koşullarının broiler verimliliğini ne ölçüde etkilediğini belirlemek amacıyla yapılan bu çalışmada, her sürünün içinde bulundurulduğu hijyen koşullarının ölçüsü olacak sayısal bir değer elde etmek için bir indeks geliştirilmiş ve geliştirilen bu indeks kullanılarak her sürüi için bir hijyen indeks değeri hesaplanmıştır. Her bir sürü için hesaplanan hijyen indeks değeri ile yine o sürüye ait broiler verimlilik indeks değeri arasındaki ilişki araştırılarak, benzer genetik potansiyele sahip sürüler arasında verimlilik açısından gözlenen farklılığın ne kadarının hijyen değişkenleri ile açıklanabileceği tartışılmıştır.

\section{Materyal ve Metot}

\section{Materyal}

Araştırma gerecini büyük bir ticari entegrasyonla sözleşmeli üretim yapan 298 broiler üretim kümesi ile bu kümeslerde 16 ay süresince üretilen toplam $1430 \mathrm{adet}$ sürü oluşturmuştur. Sürüler ilk üç hafta standart başlangıç (3000 - $3100 \mathrm{kcal} / \mathrm{kg} \mathrm{ME}, \% 23 \mathrm{HP})$ ve üç haftadan sonra büyütme / bitiş (3100 - $3200 \mathrm{kcal} / \mathrm{kg} \mathrm{ME}$, $\% 21 \mathrm{HP}$ ) rasyonları ile serbest olarak beslenmişlerdir.

\section{Metot}

Hijyen koşullarının ölçüsü olacak bir indeks geliştirmek için iki sonuçlu hijyen değişkenleri tanımlanmış (Tablo 1) ve araştırma kapsamındaki tüm sürülerde bu değişkenler ile ilgili kayıtlar tutulmuştur. Her bir sürüye ait broiler verimlilik indeks değeri (BVI) aşağıdaki formül (2) kullanılarak hesaplanmıştır.

BVİ : Yaşama Gücü (\%) x Canlı Ağırlık (kg) x 100

Kesim Yag (gün) $\times$ Yenden Yararanma

Hijyen indeksi (HI) geliştirmek için hijyen koşulları ile verimlilik arasındaki doğrusal ilişkiden yararlanılmıştır. Hijyen ve verimlilik arasındaki ilişki aşağıdaki eşitlikteki gibi tanımlanabilir:

$$
\mathrm{Y}=\mathrm{X} \beta+\mathrm{e}_{1}
$$

(Model I)

Burada; Y: verimlilik, $\mathrm{X}:$ hijyen, $\beta$ Hijyen değişkenleri için katsayı matriksi ve $e_{1}$ : Model I için rasgele hatadır. Burada hijyen (X) doğrudan ölçülemeyeceği için onun yerine hijyẹnle ilgili ölçülebilen değişkenler kullanılırsa eşitlik,

$$
\mathrm{X}=\mathrm{ZA}+\mathrm{e}_{2}
$$

(Módel II) halini alacaktır.

Burada A: Z değişkenleri için katsayı matriksi ve e2 : Model II için rast gele hatadır.

Broiler verimlilik indeksi (bağımlı değişken) ile hijyen değişkenleri (bağımsız değişken) arasında bir bilgisayar paket programda (25) adim adim regresyon (stepwise regression) analizi $(6,7)$ uygulanmıştır. Regresyon analizinde başlangıçta tüm hijyen değişkenleri modele alınmış ve her adımda en düşük katsayı ve önem düzeyine sahip değişken modelden çıkarılarak bir sonraki basamağa geçilmiştír. Modelde bulunan tüm değişkenler broiler verimlilik indeksi ile önemli ölçüde ilişkili bulununca işlem tamamlanmıştır. Son regresyon modelinde (hijyen indeksi) yer alan değişkenlerin, her bir sürüde aldıkları değerler ( 0 veya 1$)$ ile o değişkenlere ait regresyon katsayılarının çarpımlarının toplanmasıyla her bir sürü için bir $\mathrm{HI}$ değeri hesaplanmış ve hesaplạnan bu değer ile yine o sürüye ait BVİ değeri arasında korelasyon analizi (26) uygulanmıştır.

\section{Bulgular}

Araştırma sonucunda hijyen değişkenlerinin sürü düzeyinde aldığı sonuçlar Tablo 1'de sunulmuştur. Hijyen değişkenleri ile BVI arasında uygulanan Regresyon analizi sonucunda; salgın hastalık (salgın), ölen hayvanların uzaklaştırılması (ölüid), kümes yapısı (k-yapı), kümesin çevre kümeslerden uzaklı̆̆g (uzaklık), altlık materyalinin üretim periyodu sonunda uzaklaştırılması (alt-uz), kümes girişinde dezenfeksiyon

\begin{tabular}{|c|c|c|c|c|c|c|}
\hline \multirow[t]{2}{*}{ Hijyen Değişkeni } & \multirow{2}{*}{$\begin{array}{l}\text { Değişken } \\
\text { Kodu }\end{array}$} & \multirow{2}{*}{$\begin{array}{l}\text { Değişken } \\
\text { Sınırları }\end{array}$} & \multirow{2}{*}{$\begin{array}{l}\text { Sayisal } \\
\text { Kod }\end{array}$} & \multicolumn{2}{|c|}{ Sürü } & \multirow{2}{*}{$\begin{array}{c}\text { BVİ } \\
\overline{\mathbf{x}} \pm \mathbf{s}_{\overline{\bar{x}}} \\
\end{array}$} \\
\hline & & & & Sayl & $\%$ & \\
\hline \multicolumn{7}{|l|}{ 1. Kümesle ilgili hijyen değişkenleri } \\
\hline Kümesin çevre kümeslerden uzaklığı & Uzaklık & $\begin{array}{l}\geq 200 \mathrm{~m} \\
<200 \mathrm{~m}\end{array}$ & $\begin{array}{l}1 \\
0\end{array}$ & $\begin{array}{l}780 \\
650\end{array}$ & $\begin{array}{l}54.5 \\
45.5\end{array}$ & $\begin{array}{l}207.36 \pm 1.05 \\
177.37 \pm 1.36\end{array}$ \\
\hline Kümes çevresinde çit var mı? & İzolasyon & $\begin{array}{l}\text { Evet } \\
\text { Hayır }\end{array}$ & $\begin{array}{l}1 \\
0\end{array}$ & $\begin{array}{l}914 \\
1516\end{array}$ & $\begin{array}{l}63.9 \\
36.1\end{array}$ & $\begin{array}{l}206.36 \pm 0.96 \\
171.36 \pm 1.49\end{array}$ \\
\hline Kümes yaşı & K-Yaşı & $\begin{array}{l}<15 \mathrm{yll} \\
\geq 15 \mathrm{y} 1 \mathrm{l}\end{array}$ & $\begin{array}{l}1 \\
0\end{array}$ & $\begin{array}{l}499 \\
931\end{array}$ & $\begin{array}{l}34.9 \\
65.1\end{array}$ & $\begin{array}{l}209.71 \pm 1.29 \\
185.16 \pm 0.93\end{array}$ \\
\hline Taban izólasyonu & T-İzo & $\begin{array}{l}\text { Var } \\
\text { Yok }\end{array}$ & $\begin{array}{l}1 \\
0\end{array}$ & $\begin{array}{l}836 \\
594\end{array}$ & $\begin{array}{l}58.5 \\
41.5\end{array}$ & $\begin{array}{l}198.90 \pm 0.97 \\
186.45 \pm 1.13\end{array}$ \\
\hline
\end{tabular}
(dezen), kümes yaşı (k-yaşı), kümes kapasitesi (kapa- 


\begin{tabular}{|c|c|c|c|c|c|c|}
\hline \multirow[t]{2}{*}{ Hijyen Değişkeni } & \multirow{2}{*}{$\begin{array}{l}\text { Değişken } \\
\text { Kodu }\end{array}$} & \multirow{2}{*}{$\begin{array}{l}\text { Değişken } \\
\text { Sınirları }\end{array}$} & \multirow{2}{*}{$\begin{array}{l}\text { Sayısal } \\
\text { Kod } \\
\end{array}$} & \multicolumn{2}{|c|}{ Sürü } & \multirow{2}{*}{$\begin{array}{c}\text { BVÍ } \\
\bar{x} \pm s_{\bar{x}}\end{array}$} \\
\hline & & & & Sayı & $\%$ & \\
\hline $\begin{array}{l}\text { Kümes çevresinde başka tür veya ırktan } \\
\text { kanatl hayvan var m?? }\end{array}$ & Başkatür & $\begin{array}{l}\text { Evet } \\
\text { Hayır }\end{array}$ & $\begin{array}{l}1 \\
0\end{array}$ & $\begin{array}{l}602 \\
828\end{array}$ & $\begin{array}{l}42.1 \\
57.9\end{array}$ & $\begin{array}{l}171.03 \pm 1.35 \\
210.23 \pm 0.91\end{array}$ \\
\hline Kümes çatısında izolasyon maddesi var mı? & K-çatı & $\begin{array}{l}\text { Evet } \\
\text { Hayır }\end{array}$ & $\begin{array}{l}1 \\
0\end{array}$ & $\begin{array}{l}509 \\
921\end{array}$ & $\begin{array}{l}35.6 \\
64.4\end{array}$ & $\begin{array}{c}209.16 \pm 0.87 \\
185.2 \pm 1.29\end{array}$ \\
\hline $\begin{array}{l}\text { Üretim kümesi ile kuluçkahane } \\
\text { Arasındaki mesafe }\end{array}$ & Uz-kuluçka & $\begin{array}{l}<50 \mathrm{~km} \\
\geq 50 \mathrm{~km}\end{array}$ & $\begin{array}{l}1 \\
0\end{array}$ & $\begin{array}{l}879 \\
551\end{array}$ & $\begin{array}{l}61.5 \\
38.5\end{array}$ & $\begin{array}{l}195.17 \pm 0.87 \\
191.43 \pm 0.93\end{array}$ \\
\hline $\begin{array}{l}\text { Üretim kümesi ile kesimhane } \\
\text { Arasındaki mesafe }\end{array}$ & Uz-kesim & $\begin{array}{l}<50 \mathrm{~km} \\
\geq 50 \mathrm{~km}\end{array}$ & $\begin{array}{l}1 \\
0\end{array}$ & $\begin{array}{l}837 \\
593\end{array}$ & $\begin{array}{l}58.5 \\
41.5\end{array}$ & $\begin{array}{l}196.41 \pm 0.96 \\
189.94 \pm 0.94\end{array}$ \\
\hline \multicolumn{7}{|l|}{ 2. Ekipmanla ilgili hijyen değişkenleri } \\
\hline $\begin{array}{l}\text { Ekipmanlar kümes içinde homojen } \\
\text { olarak dağıtılmış mı? }\end{array}$ & Ekipman & $\begin{array}{l}\text { Evet } \\
\text { Hayır }\end{array}$ & $\begin{array}{l}1 \\
0\end{array}$ & $\begin{array}{r}1156 \\
274\end{array}$ & $\begin{array}{l}76.3 \\
23.7\end{array}$ & $\begin{array}{l}200.96 \pm 0.93 \\
163.22 \pm 1.99\end{array}$ \\
\hline Yem dağıtımı nasıl yapılıyor? & Otomasyon & $\begin{array}{l}\text { Otomatik } \\
\text { Elle }\end{array}$ & $\begin{array}{l}1 \\
0\end{array}$ & $\begin{array}{r}1016 \\
414\end{array}$ & $\begin{array}{l}71.1 \\
28.9\end{array}$ & $\begin{array}{l}203.42 \pm 0.97 \\
169.95 \pm 1.64\end{array}$ \\
\hline Yemlik tipi & Yemlik-tip & $\begin{array}{l}\text { Yuvarlak } \\
\text { Düz }\end{array}$ & $\begin{array}{l}1 \\
0\end{array}$ & $\begin{array}{r}1191 \\
239\end{array}$ & $\begin{array}{l}83.3 \\
16.7\end{array}$ & $\begin{array}{l}196.36 \pm 1.01 \\
180.60 \pm 2.19\end{array}$ \\
\hline $\mathrm{m}^{2}$ 'ye düșen yemlik payı & Y-payı & $\begin{array}{l}\geq 25 \mathrm{~cm} / \mathrm{m}^{2} \\
<25 \mathrm{~cm} / \mathrm{m}^{2}\end{array}$ & $\begin{array}{l}1 \\
0\end{array}$ & $\begin{array}{l}534 \\
896\end{array}$ & $\begin{array}{l}37.4 \\
62.6\end{array}$ & $\begin{array}{l}197.28 \pm 1.13 \\
191.28 \pm 1.63\end{array}$ \\
\hline Suluk tipi & Suluk-tip & $\begin{array}{l}\text { Plastik } \\
\text { Damlalıklı }\end{array}$ & $\begin{array}{l}1 \\
0\end{array}$ & $\begin{array}{r}1217 \\
213\end{array}$ & $\begin{array}{l}85.1 \\
14.9\end{array}$ & $\begin{array}{l}192.52 \pm 1.31 \\
200.61 \pm 1.17\end{array}$ \\
\hline $\begin{array}{c}\mathrm{m}^{2} \text { ye konan suluk miktarn } \\
.\end{array}$ & $\begin{array}{ll} & \text { Plastik } \\
\text { Sp } & \\
& \text { Nipple }\end{array}$ & $\begin{array}{l}\geq 0.2 \text { adet } / \mathrm{m}^{2} \\
<0.2 \mathrm{adet} / \mathrm{m}^{2} \\
\geq 1.5 \mathrm{adet} / \mathrm{m}^{2} \\
<1.5 \mathrm{adet} / \mathrm{m}^{2}\end{array}$ & $\begin{array}{l}1 \\
0 \\
1 \\
0\end{array}$ & $\begin{array}{r}687 \\
530 \\
177 \\
36\end{array}$ & $\begin{array}{l}56.4 \\
43.6 \\
83.1 \\
16.9\end{array}$ & $\begin{array}{l}194.78 \pm 0.98 \\
190.68 \pm 1.91 \\
198.83 \pm 1.06 \\
193.27 \pm 1.14\end{array}$ \\
\hline Aydınlatmada kullanılan ışık kaynağı & Işık-kay & $\begin{array}{l}\text { Ampul } \\
\text { Florasan }\end{array}$ & $\begin{array}{l}1 \\
0\end{array}$ & $\begin{array}{l}993 \\
437\end{array}$ & $\begin{array}{l}69.4 \\
30.6\end{array}$ & $\begin{array}{l}201.46 \pm 1.01 \\
176.16 \pm 1.72\end{array}$ \\
\hline Kümes ısıtması nasıl sağlanıyor? & Isitma & $\begin{array}{l}\text { Radyan } \\
\text { Soba }\end{array}$ & $\begin{array}{l}1 \\
0\end{array}$ & $\begin{array}{l}764 \\
666\end{array}$ & $\begin{array}{l}53.4 \\
46.6\end{array}$ & $\begin{array}{l}205.25 \pm 1.06 \\
180.51 \pm 1.29\end{array}$ \\
\hline Havalandırma nasıl yapılıyor? & Hava & $\begin{array}{l}\text { Yapay } \\
\text { Doğal }\end{array}$ & $\begin{array}{l}1 \\
0\end{array}$ & $\begin{array}{r}354 \\
1076\end{array}$ & $\begin{array}{l}24.7 \\
75.3\end{array}$ & $\begin{array}{l}214.26 \pm 1.63 \\
186.97 \pm 1.01\end{array}$ \\
\hline 3. Sürü idaresi ile ilgili hijyen değişkenleri & & & & & & \\
\hline $\begin{array}{l}\text { Kümes içi max-min sıcaklıklara göre sürü } \\
\text { soğuk stresine maruz kaldı mı? }\end{array}$ & Soğuk-st & $\begin{array}{l}\text { Hayur }\left(15 \leq^{\circ} \mathrm{C}\right) \\
\text { Evet }\left({ }^{\circ} \mathrm{C}<15\right)\end{array}$ & $\begin{array}{l}1 \\
0\end{array}$ & $\begin{array}{r}1313 \\
117\end{array}$ & $\begin{array}{c}91.8 \\
8.2\end{array}$ & $\begin{array}{l}194.06 \pm 1.30 \\
189.98 \pm 1.39\end{array}$ \\
\hline $\begin{array}{l}\text { Kümes içi max-min sıcaklıklara göre sürũ } \\
\text { sıcak stresine maruz kaldı mı? }\end{array}$ & Sicak-st & $\begin{array}{l}\text { Hayır }\left({ }^{\circ} \mathrm{C}<30\right) \\
\text { Evet }\left(30 \leq^{\circ} \mathrm{C}\right)\end{array}$ & $\begin{array}{l}1 \\
0\end{array}$ & $\begin{array}{r}1157 \\
273\end{array}$ & $\begin{array}{l}80.9 \\
19.1\end{array}$ & $\begin{array}{l}197.02 \pm 0.97 \\
179.78 \pm 1.26\end{array}$ \\
\hline Üretim dönemleri arasındaki boşluk & Dinlendirme & $\begin{array}{l}\geq 15 \text { gün } \\
<15 \text { gün }\end{array}$ & $\begin{array}{l}1 \\
0\end{array}$ & $\begin{array}{r}1084 \\
346\end{array}$ & $\begin{array}{l}75.8 \\
24.2\end{array}$ & $\begin{array}{l}195.77 \pm 1.07 \\
187.34 \pm 1.21\end{array}$ \\
\hline Kesimde $\mathrm{m}^{2,}$ ye düşen canlı ağırlık & $\begin{array}{l}\mathrm{kg} / \mathrm{m}^{2} \mathrm{Yaz} \\
\mathrm{kg} / \mathrm{m}^{2} \mathrm{~K}_{\mathrm{IS}}\end{array}$ & $\begin{array}{l}\geq 30 \mathrm{~kg} \\
<30 \mathrm{~kg} \\
\geq 35 \mathrm{~kg} \\
<35 \mathrm{~kg}\end{array}$ & $\begin{array}{l}1 \\
0 \\
1 \\
0\end{array}$ & $\begin{array}{r}218 \\
1212 \\
98 \\
1332\end{array}$ & $\begin{array}{c}15.3 \\
84.7 \\
6.8 \\
93.2\end{array}$ & $\begin{array}{l}189.71 \pm 2.08 \\
194.45 \pm 1.19 \\
208.69 \pm 1.64 \\
192.63 \pm 1.17\end{array}$ \\
\hline Kümes girişinde dezenfektan var mı? & Dezen & $\begin{array}{l}\text { Evet } \\
\text { Hayır }\end{array}$ & $\begin{array}{l}1 \\
0\end{array}$ & $\begin{array}{r}1211 \\
219\end{array}$ & $\begin{array}{l}84.7 \\
15.3\end{array}$ & $\begin{array}{l}198.77 \pm 0.94 \\
165.80 \pm 2.30\end{array}$ \\
\hline Dahili elbisesi ve çizme kullanulyyor mu? & Elbise & $\begin{array}{l}\text { Evet } \\
\text { Hayır }\end{array}$ & $\begin{array}{l}1 \\
0\end{array}$ & $\begin{array}{l}464 \\
966\end{array}$ & $\begin{array}{l}32.4 \\
67.6\end{array}$ & $\begin{array}{l}218.04 \pm 1.17 \\
182.06 \pm 1.07\end{array}$ \\
\hline $\begin{array}{l}\text { Ölen hayvanlar günlük olarak toplanıp } \\
\text { Uygun bir şekilde yok ediliyor mu? }\end{array}$ & Ölüid & $\begin{array}{l}\text { Evet } \\
\text { Hayır }\end{array}$ & $\begin{array}{l}1 \\
0\end{array}$ & $\begin{array}{r}376 \\
1054\end{array}$ & $\begin{array}{l}26.3 \\
73.7\end{array}$ & $\begin{array}{l}222.17 \pm 1.19 \\
183.59 \pm 1.02\end{array}$ \\
\hline Yemler kümesin neresinde depolanıyor? & Yem depo & $\begin{array}{l}\text { Dişında } \\
\text { İçinde }\end{array}$ & $\begin{array}{l}1 \\
0\end{array}$ & $\begin{array}{r}312 \\
1118\end{array}$ & $\begin{array}{l}21.8 \\
78.2\end{array}$ & $\begin{array}{l}221.72 \pm 1.35 \\
185.92 \pm 1.01\end{array}$ \\
\hline Suluklar günlük olarak yıkanıyor mu? & Sulukid & $\begin{array}{l}\text { Evet } \\
\text { Hayır }\end{array}$ & $\begin{array}{l}1 \\
0\end{array}$ & $\begin{array}{r}1231 \\
199\end{array}$ & $\begin{array}{l}86.1 \\
13.9\end{array}$ & $\begin{array}{l}199.22 \pm 0.92 \\
159.79 \pm 2.41\end{array}$ \\
\hline Altlik materyali & Altlık-mat & $\begin{array}{l}\text { Talaş } \\
\text { Diğer }\end{array}$ & $\begin{array}{l}1 \\
0\end{array}$ & $\begin{array}{r}324 \\
1106\end{array}$ & $\begin{array}{l}22.7 \\
77.3\end{array}$ & $\begin{array}{l}208.62 \pm 1.14 \\
189.37 \pm 2.38\end{array}$ \\
\hline $\mathrm{m}^{2}$ ye konan altlık miktarn & Altlıkmik & $\begin{array}{l}\geq 3 \mathrm{~kg} \\
<3 \mathrm{~kg}\end{array}$ & $\begin{array}{l}1 \\
0\end{array}$ & $\begin{array}{r}189 \\
1241\end{array}$ & $\begin{array}{l}13.2 \\
86.8\end{array}$ & $\begin{array}{l}197.49 \pm 1.34 \\
191.73 \pm 1.63\end{array}$ \\
\hline $\begin{array}{l}\text { Üretim döneminde keçeleşen altlık } \\
\text { Değiştiriliyor mu? }\end{array}$ & Alt-ilave & $\begin{array}{l}\text { Evet } \\
\text { Hayır }\end{array}$ & $\begin{array}{l}1 \\
0\end{array}$ & $\begin{array}{r}397 \\
1033\end{array}$ & $\begin{array}{l}27.8 \\
72.2\end{array}$ & $\begin{array}{l}206.94 \pm 0.98 \\
188.65 \pm 1.25\end{array}$ \\
\hline $\begin{array}{l}\text { Altlık materyali üretim sonunda güvenli } \\
\text { Bir uzaklığa bırakılıyor mu? }\end{array}$ & Alt-uz & $\begin{array}{l}\text { Evet } \\
\text { Hayır }\end{array}$ & $\begin{array}{l}1 \\
0\end{array}$ & $\begin{array}{l}575 \\
855\end{array}$ & $\begin{array}{l}40.2 \\
59.8\end{array}$ & $\begin{array}{l}215.37 \pm 0.97 \\
179.16 \pm 1.17\end{array}$ \\
\hline
\end{tabular}




\begin{tabular}{|c|c|c|c|c|c|c|}
\hline \multirow[t]{2}{*}{ Hijyen Değişkeñi } & \multirow{2}{*}{$\begin{array}{l}\text { Değişken } \\
\text { Kodu }\end{array}$} & \multirow{2}{*}{$\begin{array}{l}\text { Değişken } \\
\text { Sunırları }\end{array}$} & \multirow{2}{*}{$\begin{array}{l}\text { Sayısal } \\
\text { Kod } \\
\end{array}$} & \multicolumn{2}{|c|}{ Sürü } & \multirow{2}{*}{$\begin{array}{l}\text { BVI } \\
\frac{1}{1} \pm S_{\overline{3}}\end{array}$} \\
\hline & & & & Sayı & $\%$ & \\
\hline Kemiricilerle mücadele programi var $\mathrm{m} 1 ?$ & Kemirici & $\begin{array}{l}\text { Evet } \\
\text { Hayır }\end{array}$ & $\begin{array}{l}1 \\
0\end{array}$ & $\begin{array}{r}258 \\
1172\end{array}$ & $\begin{array}{l}18 \\
82\end{array}$ & $\begin{array}{l}210.36 \pm 1.23 \\
190.07 \pm 2.16\end{array}$ \\
\hline 4. Sürü sağhı̆ı ile ilgili hijyen değişkenleri & & & & & 1 & \\
\hline İlk hafta ölümlerinin toplam sürüye oranı & İlk hafta & $\begin{array}{l}<\% 3.5 \\
\geq \% 3.5\end{array}$ & $\begin{array}{l}1 \\
0\end{array}$ & $\begin{array}{l}617 \\
813\end{array}$ & $\begin{array}{l}43.1 \\
56.9\end{array}$ & $\begin{array}{l}197.61 \pm 0.98 \\
190.79 \pm 1.26\end{array}$ \\
\hline $\begin{array}{l}\text { Üretim döneminde bir salgın hastalık } \\
\text { Gözlendi mi? }\end{array}$ & Salgın & $\begin{array}{l}\text { Evet } \\
\text { Hayir }\end{array}$ & $\begin{array}{l}1 \\
0\end{array}$ & $\begin{array}{l}482 \\
947\end{array}$ & $\begin{array}{l}33.8 \\
66.2\end{array}$ & $\begin{array}{l}167.18 \pm 2.68 \\
207.45 \pm 1.12\end{array}$ \\
\hline
\end{tabular}

site), kümesin havalandırılması (hava), kümes çevresinde başka tür ya da 1rktan kanatlı hayvanın bulunup bulunmaması (başkatür) ve kümesin 1sıtılması (isıtma) değişkenlerinden oluşan ve BVİ değerini önemli ölçüde etkileyen bir hijyen indeksi (Hİ) geliştirilmiştir.

Geliştirilen regresyon modelinin belirtme katsayısı $\left(\mathrm{R}^{2}\right) \quad 0.494$ olup, model istatistik açıdan önemli

Tablo 2: Hijyen indeksinde yer alan hijyen değişkenleri

Table 2: Hygiene variables that significantly associated with EEF

\begin{tabular}{llll}
\hline Değişken kodu & Katsayı & Std. Hata & Önem Düzeyi \\
\hline Salgın & -9.671 & 1.063 & 0.000 \\
Ölüid & 9.663 & 2.063 & 0.006 \\
K-yapı & 9.641 & 2.085 & 0.036 \\
Uzaklık & 9.683 & 1.868 & 0.029 \\
Alt-uz & 9.356 & 2.153 & 0.046 \\
Dezen & 9.176 & 1.696 & 0.039 \\
K-yaşı & 8.448 & 1.883 & 0.044 \\
Kapasite & 7.976 & 1.112 & 0.047 \\
Hava & 6.672 & 1.327 & 0.049 \\
Başkatür & -5.163 & 2.099 & 0.038 \\
Isıtma & 5.071 & 1.898 & 0.004 \\
\hline
\end{tabular}

Model Belirtme Katsayısı (R2)

0.494

$(\mathrm{p}<0.001)$ bulunmuştur. Sonuç olarak hijyen indeksi şu şekilde oluşmuştur;

$\mathrm{HI}=\mathrm{f}$ (salgın, ölüid, k-yapı, uzaklık, alt-uz, dezen, k-yaşı, kapasite, hava, başkatür, ısıtma).

Hijyen indeksinde yer alan değişkenler, değişkenlere ait katsayılar, katsayılara ait standart hatalar ve önem düzeyleri Tablo 2'de sunulmuştur.

Hijyen indeksinde yer alan değişkenlerin her bir sürüde aldıkları değerler (0 ya da 1) ile o değişkenlere ait katsayıların çarpımlarının toplanması ile tüm sürüler için hijyen indeks değerleri hesaplanmış ve frekans dağılım grafiği Şekil 1 'de sunulmuştur. En düşük, en yüksek ve ortalama Hİ değerleri sırasıyla $\div 14.83 ; 75.64$ ve 40.20 olarak belirlenmiştir.

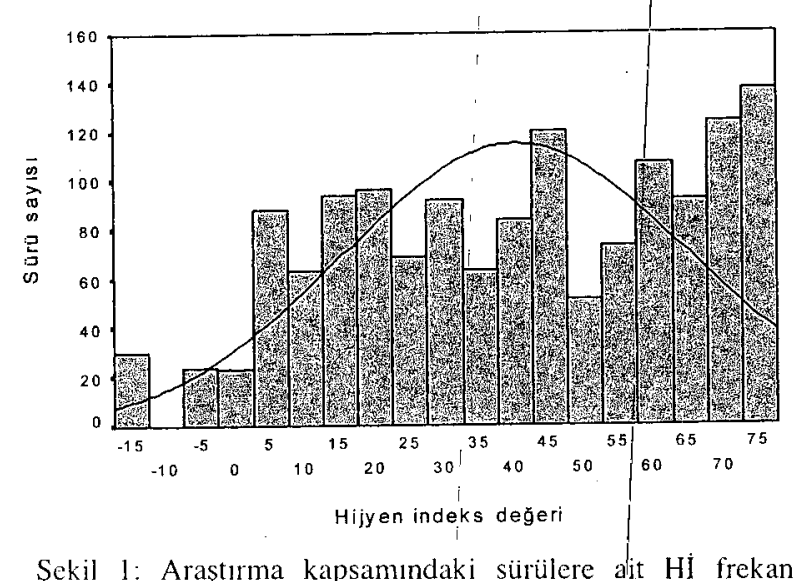

Şekil 1: Araştırma kapsamındaki sürülere alit $\mathrm{HI}$ frekans dağılım grafiğ i

Figure 1: Distribution of hygiene index scores

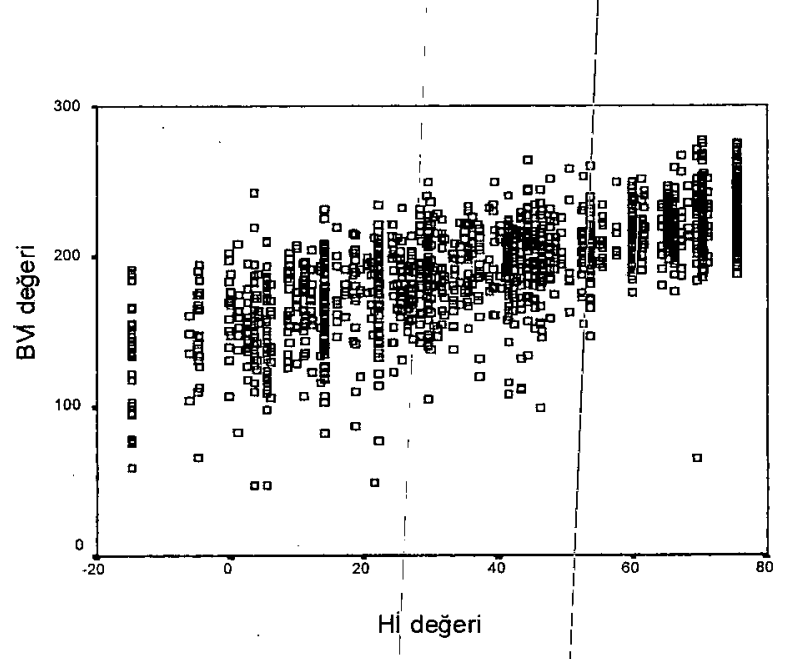

Şckil 2: BVI de ğeri ile HI değeri arasındakli serpilme grafiği $(\mathrm{p}<0.01)$.

Figure 2: Correlation between hygiene index and European Efficiency Factor 
Her bir sürü için hesaplanan Hİ değeri ile o sürüye ait BVİ değeri arasında uygulanan korelasyon analizi sonucunda BVİ ile Hİ arasında yüksek düzeyde bir korelasyon $(r=0.703)$ bulunduğu ve iki değişken arasındaki ilişkinin istatistik açıdan önemli $(\mathrm{p}<0.01)$ olduğu belirlenmiştir (Şekil 2).

\section{Tartışma ve Sonuç}

Hİ geliştirmek amacıyla kurulan regresyon modelinin belirtme katsayısının $\mathrm{R}^{2}=0.494$ olarak bulunmuş olması, BVİ değerleri açısından sürüler arasında gözlenen farklılığın \%49'unun Hİ'nde yer alan değişkenlerle açıklanabileceği anlamına gelmektedir. Broiler verimliliğini etkileyen pek çok faktör olduğu düşünüldüğünde, hijyen değişkenlerinin verim özellikleri üzerinde önemli ölçüde etkili olduğu görülmektedir.

Geliştirilen hijyen indeksinde yer alan en yüksek mutlak değere sahip değişkenin "salgın hastalık" olması, hayvansal üretimde üstün verim özelliklerinin ancak sağ hkklı sürülerden elde edilebileceğini bildiren klasik kaynaklarla $(2,22)$ uyum içindedir. Hastalıklar, doğrudan yaşama gücü üzerinde olumsuz etki oluşturarak verimliliği olumsuz etkilemelerinin yanı sıra, yem tüketimi ve yemden yararlanma oranını da olumsuz etkileyerek BVİ değerinin düşmesine yol açmaktadır.

Ölen hayvanların günlük olarak toplanı uygun bir şekilde yok edilmesi, hastahk etkenlerinin uzak tutulması ve optimum hijyen koşullarının sağlanması için uyulması gereken en önemli sağlık koruma kurallarından biridir. Bu uygulamanın yapılmaması çeşitli hastalık etkenlerinin üretim alanı ve sürü etrafında varlığını sürdürmesine neden olmakta ve özellikle giriş / çıkış kontrolü iyi yapılmayan üretim kümeslerinde bulaşmanın kolaylaşmasına yol açmaktadır. Nitekim, ölen hayvanların günlük olarak toplanıp uygun bir şekilde yok edilmemesi broiler sürülerde cellulitis ve campylobacter hastalıkları için önemli bir risk faktörü olarak bildirilmiştir $(10,11)$.

Kümes yapısı verimliliği önemli ölçüde etkilemektedir (Tablo1). Kümes yapısının verimliliğe etkisi, muhtemelen üretim dönemi sonunda uygulanan temizlik ve dezenfeksiyonun beton yüzeylerde diğer yapı malzemelerine göre daha etkili olmasindan kaynaklanmaktadır. Nitekim, broiler sürülerde koksidiyozis ile ilgili risk faktörlerinin belirlenmesi amacıyla yapılan bir araştırmada (12), kümeslerin kolay temizlenebilir bir niteliğe sahip olmaması önemli bir risk faktörü olarak bildirilmiştir.

Kümesler arasındaki mesafe ile broiler verimliliği arasında pozitif yönlü ve önemli bir ilişki olduğu belirlenmiştir. Kümesler arası mesafenin fazla olması, hastalık etkenlerinin uzak tutulması ve kümes çalışanlarının diğer kümeslerle ilişki içinde olmasııın engellenmesi yoluyla, uygun hijyen koşullarının sağlanması ve bu yolla verimliliğin artmasına yol açmış olabilir. Araştırma bulguları, ziyaret sıklığ1
$(1,21,28)$, çiftlik personelinin diğer çiftliklerle ilişkili olması (12), birden çok kişinin aynı kümeslere bakması (23) ve kümese teknik servis sağlayan kişilerin araçları ile birlikte çiftliğin içine kadar girmesi $(20,24)$ gibi faktörleri çeşitli sağlık sorunları için risk faktörï olarak bildiren çalışmalarla benzer bulunmuştur.

Araştırma sonucunda, altllğın her üretim dönemi sonunda çıkarılıp güvenli bir uzaklığa bırakılmasının verimliliği önemli ölçüde arttırdı ̆̆ belirlenmiştir. Eski altığın uzaklaştırılmaması bazı hastalık etkenleri ve fare, sinek vb gibi çeşitli zararlıların kümes çevresine yerleşmeleri ve sürüyü tehdit etmelerine yol açmaktadır. Araştırma bulguları, sağlıklı yaşam koşulları için altlı̆̆ın güvenli bir uzaklığa birakılması gerektiğini bildiren araştırmalarla $(3,20,29)$ uyumlu bulunmuştur.

Araştırma sonucunda, kümes girişinde dezenfeksiyon uygulamasının yapılmaması, verimliliği önemli ölçüde düşürren bir etken olarak belirlenmiştir. Uygun bir dezenfektan madde ile kümes içinde kullanılacak çizmelerin dezenfekte edilmesi temel sağlık koruma kurallarından biridir. Dezenfeksiyon işleminin yapılmaması hastalık etkenlerinin bakıcılar ve/veya ziyaretçiler tarafından kolayca sürüye bulaşturılmasına yol açabilir. Araşıırma sonuçları, kümes girişinde dezenfeksiyon yapılmamasını çeşitli hastalık etkenleri için risk faktörü olarak bildiren araştırmalarla $(11,16,30)$ uyumludur.

Kümes yaşııın 15 'in üzerinde olması broiler verimliliğini olumsuz yönde etkilemektedir. Bu durum, kümes yaşı arttıkça hayvanlara sağlanması gereken optimum çevre koşullarının sağlanmasında güçlüklerle karşılaşııldığını düşündürmektedir. Araşıırma sonuçları, kümes yaşının artması ve kümeslerin yapısal bir bakım gerektirmesinin yaşama gücü ve sürü sağllı̆̆ üzerinde olumsuz bir etkiye sahip olduğunu bildiren araştırma sonuçlarıyla $(11,14)$ paralellik göstermektedir.

Kümes kapasitesinin 5000 ve üzerinde olmasınn hijyen indeksini ve dolayısıyla da verimliliği artırdığı belirlenmiştir. Kümes kapasitesi arttıkça verimliliğin artması, büyük kapasiteli kümeslerin görece daha yeni olmaları, bu kümeslerde kullanılan ekipmanların hayvan davranı̧̧larına daha uygun tasarlanmış olması, daha yüksek yatırım gerektirmeleri nedeni ile üretim önceliğine sahip olmaları ve büyük kapasiteli kümeslere sahip işletmecilerin bilinç düzeyinin daha yüksek olmasından kaynaklanmış olabilir. Araştırma sonuçları sürü büyüklüğü ile salmonella enfeksiyonu arasında pozitif yönlü ve önemli bir ilişki olduğunu bildiren araştırma bulguları (17) ile uyuşmamaktadır. Bu durum, araştırmalarda kullanılan kapasite sınırlarının birbirinden önemli ölçüde farklı olmasından kaynaklanmış olabilir.

Araştırma sonucunda, doğal havalandırmalı kümeslerde, yapay havalandırmalı kümeslere göre daha düşük verimlilik değerleri elde edilmiştir. Yapay havalandırmalı kümeslerin verimlilik üzerindeki olumlu etkisi özellikle yaz mevsiminde gözlenen yüksek 
Sıcaklıklarda doğal havalandırmalı kümeslerin optimum havalandırmayı sağlamada yetersiz kalmalarından kaynaklanmış olabilir. Havalandırmanın sadece temiz hava sağlamak değil, bunun yanı sıra kümes içi sıcaklık, nem ve amonyak miktarının kontrol edilmesinde de önemli bir etkisi vardır. Araştırma sonuçları, yetersiz havalandırmanın çeşitli sağlık sorunları ve verim düşüklüklerine yol açtığını bildiren $(5,8,19,23,27)$ araştırmalarla uyumludur.

Kümes çevresinde başka tür, 1rk veya yaş grubundan kanath hayvan bulunması broiler verimliliğini önemli ölçüde azaltan bir faktör olarak belirlenmiştir (Tablo1). Bu durum; hastalık etkenlerinin bu hayvanlar aracılı̆̆ıyla çevrede sürekli olarak bulunması ve farklı yaş grubundaki hayvanların bağışılılı ya da duyarlılık düzeylerinin farklı olmasına bağlı olarak hastahk riskine yol açmasından kaynaklanmış olabilir. Bu bulgular, kümes çevresinde başka tür, ırk ya da yaş grubundan kanatlı hayvanların bulunmasının çeşitli hastalık etkenleri için önemli bir risk faktörü olduğunu bildiren araştırmalarla $(4,9,13,18,25)$ uyumludur.

Araştırma sonucunda, kümeslerin soba yerine radyanla ısıtılmasının verimlilik açısından önemli bir artışa yol açtığ 1 belirlenmiştir. Radyan kullanımının broiler verimliliğini arttırması, sağlanması gereken sıcaklıklara göre ayarlanabilir olması, devamlı ve sabit bir sıcaklık sağlaması nedeni ile kümes içi sıcaklığında bir dalgalanmaya yol açmaması, soba kullanımında olduğu gibi kirlenme (kömür tozu, kül, duman vb.) ve zehirlenmelere yol açmaması ve idaresinin daha kolay olmasından kaynaklanmış olabilir. Araştırma bulguları, 2-5 inci haftalar arasında gözlenen ölüm oranının, kümes ısıtmasının otomatik olarak kontrol edildiği kümeslerde elle kontrol edilenlere göre önemli ölçüde düşük olduğunu bildiren araştırma (14) bulguları ile uyumlu bulunmuştur.

Araştırma sonucunda, hijyen değişkenlerinin broiler verimliliğini önemli ölçüde etkilediği ve ölen hayvanların uzaklaştırılması, kümes çevresinde başka tür, ırk ya da yaş grubundan kanatlı hayvan barındırılmaması, altlı̆̆ın üretim dönemi sonunda uygun bir şekilde uzaklaştırılması, kümes girişinde dezenfeksiyon uygulamasının yapılması, kümesin yeterli düzeyde havalandırılması ve uygun bir şekilde ısıtılması gibi bazı hijyen değişkenlerinde yapılacak iyileştirmeler ile verimlilikte önemli artışların sağlanabileceği sonucuna ulaşılmıştır.

\section{Kaynaklar}

1. Akhtar S, Zahid S, Khan MI (1992): Risk factors associated with hydropericardium syndrome in broiler flocks. Vet Rec, 131, 481-484.

2. Aksoy FT (1999): Tavuk Yetiştiriciliği. 3. Baskı, Şahin Matbaası, Ankara.

3. Amir H, Nilipour AH (1996): Biosecurity is the bottom line. World Poultry, 12, 17-19.

4. Angen Ø, Skov MN, Chriél M, Agger JF, Bisgaard M (1996): A Retrospective study on Salmonella infection in Dannish broiler flocks. Prev Vet Med, 26, 223237.

5. Carr LE, Mallinson ET, Tate CR, Miller RG, RussekCohen E, Stewart LE, Opara OO, Josep SW (1995): Prevalence of Salmonella in broiler flocks: effect of litter water activity, house construction, and watering devices. Avian Dis, 39, 39-44

6. Dohoo IR, Ducrot C, Fourichon C, Donald A, Hurnik D (1997): An overview of techniques for dealing with large numbers of independent variables in eppidemiological studies. Prev Vet Med, 29, 221-239.

7. Draper NR, Smith H (1966): Applied Regression Analysis. John Wiley \& Sons Inc., New York.

8. Ekstrand C, Algers B, Svedberg J (1997): Rearing conditions and food-pad dermatitis in Swedish broiler chickens. Prev Vet Med, 31, 167-174.

9. Elfadil AA, Vaillancourt JP, Meek AH, Gyles CL (1996): A prospective study of cellulitis in brbiler chickens in Southern Ontario. Avian Dis, 40, 677-689.

10. Elfadil AA, Vaillancourt JP, Meek AH (1996): Farm management risk factors associated with cellulitis in broiler chickens in Southern Ontario. Avian Dis, 40,699706.

11. Evans SJ, Sayers AR (2000): A longitudinal study of campylobacter infection of broiler flocks in Great Britain. Prev Vet Med, 46, 209-223.

12. Graat EAM, Van der Kooij E, Frankena K, Henken AM, Smeets JFM, Hekerman MTJ (1998): Quantifying risk factors of coccidiosis in broilers using on-farm data based on a veterinary practice. Prev Vet Med, 33, 297. 308.

13. Hald B, Wedderkopp A, Madsen M (2000): Termophilic campylobacter, spp. in Danish broiler production: a cross-sectional, survey and a retrospective analysis of risk factors for occurrence in broiler flocks. Avian Pathol, 29, 123-131. ।

14. Heier BT, Hogasen HR, Jarp J (2002) Factors associated with mortality in Norwegian broiler flocks. Prev Vet Med, 53, 147-158.

15. Heier BT, Jarp J (2000):' Risk factors for Marek's disease and mortality in white leghorns in Norway. Prev Vet Med, 44, 153-165.

16. Henken AM, Frankena K, Goelema JO, Graat EA, Noordhuizen JP (1992): Multivariate epidemiological approach to salmonellosis in broiler breeder flocks Poultry Sci, 71, 838-843.

17. Henken AM, Goelema JO, Neijenhuis F, Vertommen MH, Van Den Bos J, Fris C (1992): Multivariate epidemiological approach tolcoccidiosis in broilers. Poultry Sci, 71, 1849-1856

18. Kapperud G, Skjeve E, Vik L, Hauge K, Lysaker A, Aalmen I, Ostroff 'SM, Potter M (1993): Epidemiological investigation of risk factors for campylobacter colonization in Norwegiah broiler flocks. Epidemiol Infect, 111, 245-255.

19 Martranchar A, Boillettot E, Huonnic D, Pol F (2002): Risk factors for foot-pad dermatitis in chicken and turkey broilers in France. Prev Vet Med, 52,213-226.

20. Mohammed HO, Carpenter TE (1991): Use of multivariable indexing score for hygiene variables in relation 10 egg production. Am J/Vet Res, 52, 970-73.

21. Nespeca R, Vaillancourt JP, Morgan Marrow WE (1997): Validation of a poultry bio-security survey. Prev Vet Med, 31, 73-86. 
22. North MO (1972): Commercial Chicken Production Manual. The Avi Publishing Company, INC. Westport, Connecticut.

23. Refrégier-Petton J, Rose N, DeNis M, Salvot G (2001): Risk factors for campylobacter spp. contamination in French broiler-chicken flocks at the end of the rearing period. Prev Vet Med, 50, 89-100.

24. Rose N, Beaudeau F, Drouin NP, Toux JY, Rose V, Colin P (2000): Risk factors for salmonella persistence after cleansing and disinfection in French broiler-chicken houses. Prev Vet Med, 44, 9-20.

25. SPSS 8.0. for Windows. Release 8.0.0 (22 Dec 1997), Standart Version, SPSS Inc., USA.

26. Sümbüllüoğlu K, Sümbüllïoğlu V (2000): Biyoistatistik. 9. Baskı, Hatipoğlu Yayınları: 53, Şahin Matbaası, Ankara.

27. Tablante NL, Brunet PY, Odor EM, Salem M, HarterDennis JM, Hueston WD (1999): Risk factors associated with early respiratory disease complex in broiler chickens. Avian Dis, 43, 424-428.

28. Vaillancourt JP (2002): Biosecurity now. Poultry International, 41, 12-18.

29. Valli L (1992): Poultry manure drying in deep pit plants. World Poultry-Misset, 8, 29-31.

30. Van De Giessen AW, Tilburg JJ, Ritmeester WS, vad der Plas J (1998): Reduction of campylobacter infections in broiler flocks by application of hygiene measures. Epidemiol Infect, 121, 57-66.

Geliş Tarihi 19.02.2003 Kabul Tarihi 02.06.2003

\section{Yazışma adresi:}

Yard. Doç. Dr. Mehmet N. ORMAN

Ankara Universitesi Veteriner Fakültesi

Biyometri Anabilim Dalt

06110 Ankara 